\title{
C-Leakage: Cylinder LPG Gas Leakage Detection for Home Safety
}

\author{
T.Soundarya ${ }^{1,}$ J.V. Anchitaalagammai ${ }^{2}$, G. Deepa Priya ${ }^{3}$, S.S. Karthick kumar ${ }^{4}$ \\ ${ }^{1} P G$ student, ${ }^{2}$ Assistant Professor III, ${ }^{3} P G$ student, $P G$ student ${ }^{4}$ \\ Department of Computer Science and Engineering, Velammal College of Engineering and Technology, \\ Madurai, India.
}

\begin{abstract}
Home Fires have taken a growing toll in lives and property in recent years. LPG is highly inflammable and can burn even at some distance from the source of leakage. Most fire accidents are caused because of a poor-quality rubber tube or when the regulator is not turned off. The supply of gas from the regulator to the burner is on even after the regulator is switched off. By accident, if the knob is turned on results in the gas leaks. This paper deals with the detection, monitoring and control system of LPG leakage. Using relay DC motor the stove knob is automatically controlled. Along with safety measures the system has additional advantage of automatic rebooking of cylinder when the level of gas goes below the normal weight of cylinder.
\end{abstract}

Keywords: Gas Leakage detection, Gas sensor, GSM, DC Motor, Knob control, Microcontroller.

\section{Introduction}

The LPG is finding wide range in homes, industries and in automobiles as fuels. In the year 1910 LPG[1], first produced by Dr.Walter Snelling the U.S Bureau of mines investigated gasoline to see why it evaporated so fast and discovered that the evaporating gases were propane, butane and other light hydrocarbons. Both LPG and natural gas are environmental friendly they easily be detected These gases are normally stored in pressurized Steel cylinders in liquid form and vaporize at normal temperatures. With comparison of air LPG is heavier therefore it flows along the floor and also settles in low points which make it difficult to disperse. LPG is a mixture of commercial butane and commercial propane having both saturated and unsaturated hydrocarbons.LPG marketed in India shall be governed by Indian Standard Code IS-4576 and the test methods by IS-1448.

Characteristics of this dangerous gas include (a) vapor pressure: The pressure inside a LPG storage vessel/ cylinder will be equal to the vapor pressure corresponding to the temperature of LPG in the storage vessel. The vapor pressure is dependent on temperature as well as on the ratio of mixture of hydrocarbons; (b) Flammability: LPG has an explosive range of $1.8 \%$ to $9.5 \%$ volume of gas in air. This is considerably narrower than other common gaseous fuels; (c) Combustion: The combustion reaction of LPG increases the volume of products in addition to the generation of heat. LPG requires up to 50 times its own volume of air for complete combustion;(d) Odour: LPG has only a very faint smell, and consequently, it is necessary to add some odourant ,so that any escaping gas can vapor phase, but can, however, suffocate when in large concentrations due to the fact that it displaces oxygen.;(e) Toxicity: LPG even though slightly toxic, is not poisonous in can pose a serious effect if they leak. Impacts: LPG may leak as a gas or a liquid. If the liquid leaks it will quickly evaporate and form a relatively large cloud of gas which will drop to the ground, as it is heavier than air. LPG vapors can run for long distances along the ground and can collect in drains or basements Cylinders can explode if involved in a fire. The health impact this dangerous gas can cause cold burns to the skin and it can act as an asphyxiant at high concentrations. Leak cause a negative effect to the health such that the hydrocarbons and other chemicals of the LPG causes very long sleep. It also causes irritated respiratory tract, nose and eyes.

\section{Problem Statement}

Gas leakage leads to various accidents resulting into both financial loss as well as human injuries. In human's daily life, environment gives the most significant impact to their health issues. The risk of firing, explosion, suffocation all are based on their physical properties such flammability, toxicity etc. The number of deaths due to the explosion of gas cylinders has been increasing in recent years. The reason for such explosion is due to sub standard cylinders, old valves, worn out regulators and lack of awareness using gas cylinders add to the risks.

Inspections by oil companies found that many LPG consumers are unaware of safety checks of gas cylinders. Another reason is illegal filling of gas cylinder also causes accidents. There is a need for a system to detect and also prevent leakage of LPG. 


\begin{tabular}{|l|l|l|}
\hline Types & Gases & Representation \\
\hline Flammable & $\begin{array}{l}\text { Methane } \\
\text {,butane } \\
\text { LPG ,propane }\end{array}$ & $\begin{array}{l}\text { Hydrogen } \\
\text { carbon } \\
\text { monoxide } \\
\text { fire, explosion of }\end{array}$ \\
\hline Toxic & $\begin{array}{l}\text { Oxygen } \\
\text { deficiency } \\
\text { Asphyxiant }\end{array}$ \\
\hline poisoning of
\end{tabular}

Figure 1: Types of hazardous gas and their risks

Necessity for detection: The consumers have to upgrade their safety standards, act in accordance with statutory requirements on

Environmental commitments and most importantly the basic function being prevented by accidents and protect life and property from disasters.

\begin{tabular}{|l|l|l|l|}
\hline 1 minute & 5 minute & $15 \mathrm{~min}$ & $60 \mathrm{~min}$ \\
\hline $3 \%$ & $2.5 \%$ & $2.0 \%$ & $1 \%$ \\
\hline
\end{tabular}

Figure 2: Typical threshold value of LPG:

Thus it takes nearly $60 \min [2][11]$ to detect when $1 \%$ of gas leak occurs. As a solution for the problem, a monitoring system of gas detector by wireless system needs to be developed in order to solve the problem. By monitoring system wirelessly, user can remotely view the condition of the home without them being there themselves.

\section{System Overv0iew}

The system overview comprises of block diagram which includes microcontroller, weight sensor, level sensor, GSM, Alarm unit and Knob control.

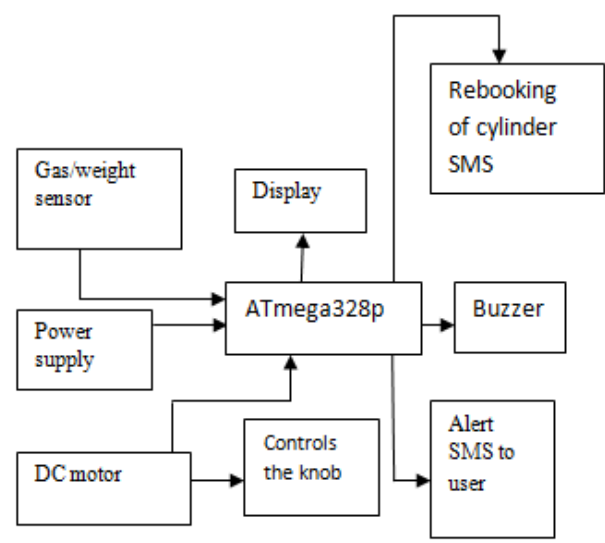

Figure 3: System Block diagram

\subsection{Microcontroller}

An efficient and smooth working controller is needed to continuously sense both leakage and level of the gas. And also fast response is require when leakage found .Along with this the monitoring system must provide additional leakage information which can be used in further processing. The detection system includes Arduino duemilanove[3] microcontroller board which is Arduino compatible with microcontroller chip ATmega328p. The Duemilanove is a microcontroller breakout board featuring ATmega328 based on the popular Arduino Footprint. It has 14 digital input/output pins (of which 6 can be used as PWM outputs), 6 analog inputs, a $16 \mathrm{MHz}$ ceramic resonator, a USB connection, a power jack, an ICSP header, and a reset button. 


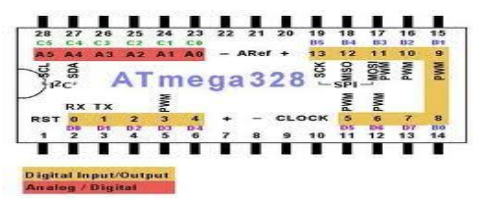

Figure 4: ATmega328 p microcontroller

The Arduino Duemilanove has a number of facilities for communicating with a computer, another Arduino, or other microcontrollers. The ATmega328 provide UART TTL $(5 \mathrm{~V})$ serial communication, which is available on digital pins 0 (RX) and 1 (TX). An FTDI FT232RL on the board channels this serial communication over USB and the FTDI drivers (included with Windows version of the Arduino software) provide a virtual com port to software on the computer. The device operates between 1.8-5.5 volts. By executing powerful instructions in a single clock cycle, the device achieves throughputs approaching 1 MIPS per MHz, balancing power consumption and processing speed. The key parameters of Atmega328p are Flash(32 kilobytes), pin count32 , maximum operating frequency $(20 \mathrm{MHz})$, maximum input/output pins(23) and no interface.

\subsection{Gas Sensor}

The LPG gas consists of isobutene, propane, methane, etc. A sensitive, efficient gas sensor is required that senses only LPG gas contents and is less sensitive to other gases like cooking fumes, cigarettes, etc. Sensitive material of MQ-6 gas sensor is $\mathrm{SnO} 2$, which with lower conductivity in clean air.

Table 1: Parts and Materials of gas sensor

\begin{tabular}{|l|l|l|}
\hline Parts No & Parts & Material \\
\hline 1. & Gas sensing layer & $\mathrm{Sno}_{2}$ \\
\hline 2. & Electrode & $\mathrm{Au}$ \\
\hline 3. & Electrode line & $\mathrm{Pt}$ \\
\hline 4. & Heater coil & $\mathrm{NI}-\mathrm{cr}^{\text {Alloy }}$ \\
\hline 5. & Tubular Ceramic & $\mathrm{Al}_{2} \mathrm{O}_{3}$ \\
\hline 6. & Anti explosion network & $\mathrm{Stainless} \mathrm{steel} \mathrm{gauze}$ \\
\hline 7. & & \\
\hline 8. & Clamp ring & Copper plating \\
\hline 9. & Resin base & Bakelite \\
\hline
\end{tabular}

(MQ6)

When the target combustible gas exist the sensor's conductivity is higher along with the gas concentration rising.

MQ-6 gas sensor [4][10] has high sensitivity to Propane, Butane and LPG, also response to Natural gas. The sensor could be used to detect different combustible gas, especially Methane, it is with low cost and suitable for different application. It senses the leakage of LPG gas and sends the alert signal to the microcontroller (ATmega328) alternatively turn on Buzzer when it reaches the danger level.

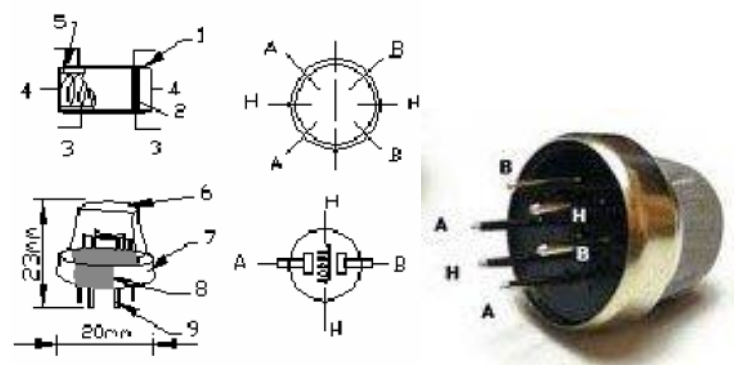

Figure 5: The structure and configuration of MQ6 gas sensor

Structure and configuration of MQ-6 gas sensor shown in the above figure composed by micro AL2O3 ceramic tube, Tin Dioxide ( $\mathrm{SnO} 2)$ sensitive layer, measuring electrode and heater are fixed into a crust made by plastic and stainless steel. The heater provides necessary work conditions for work of sensitive components. The enveloped MQ-4 have 6 pin, 4 of them are used to fetch signals, and other 2 are used for providing heating current. 
The basic test loop of gas sensor shown in below figure includes following specification. Thus the sensor need to be put VH used to supply certified working temperature to the sensor, while VC used

to detect voltage (VRL) on load resistance whom is in series with sensor. The sensor has light polarity, Vc need DC power. VC and VH could use same power circuit with precondition to assure performance of sensor. In order to make the sensor with better performance, suitable RL value is needed.

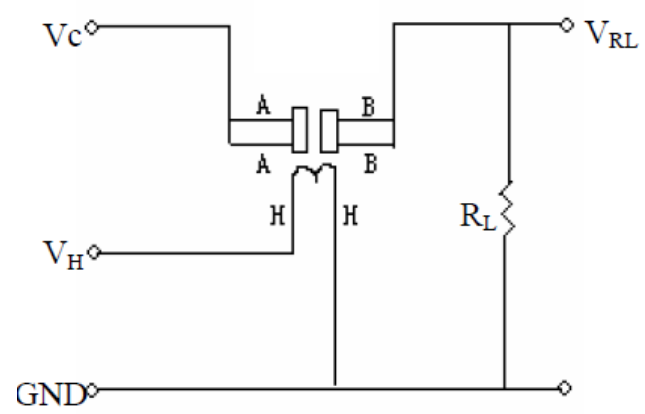

Figure 6: Test circuit of sensor

Calculation: power of sensitivity $\mathrm{Ps}=\mathrm{Vc} 2 \times \mathrm{Rs} /(\mathrm{Rs}+\mathrm{RL}) 2$

Resistance of sensor $(\mathrm{Rs})$ : $\mathrm{Rs}=(\mathrm{Vc} / \mathrm{VRL}-1) \times \mathrm{RL}$

\subsection{Weight sensor:}

There must be aware in advance of amount of gas in the cylinder, before rebooking the cylinder to the distributor. For this purpose the weight sensor is used, thus it monitors the level of gas present in the cylinder .for calibration purpose the weight sensor is used along with load cell.

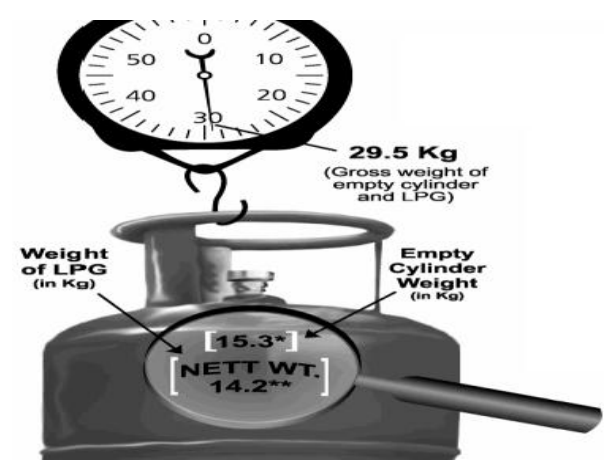

Figure 7: Weight of normal LPG gas cylinder:

Usually Permissible net weight of LPG in domestic cylinder is $14 . \mathrm{kg}+/-150 \mathrm{gm}$. The weight of empty cylinder is $15.3 \mathrm{~kg}$. The total cross weight of cylinder is determined as $29.5 \mathrm{~kg}$ [5]. Thus when it reaches $0.5 \mathrm{~kg}$ the sensor sends the signal to controller to provide refilling of cylinder through GSM

\subsection{Display:}

It is necessary requirement to put a display about system monitoring and controlling performance, which displays the various messages such as leakage of gas detection, booking of cylinder in case of refilling of cylinder .Additionally the system also, displays the actions carried out in the microcontroller. For the work of displaying the alert messages Liquid crystal display (LCD) of $16 * 2$ characters operating on +5 volt supply and operated 4-bit mode is implemented.

\subsection{GSM}

The GSM modem is highly flexible plug and play modem based on tri-band sim 300 .

Sim300 can fit almost all the space requirements in much real-time application. This global system for mobile communication technology making it very easy to send and receive the messages support the AT commands. These commands can be implemented by interfacing to the receiver and transmitter pins of microcontroller. MQ6 gas sensor detects the leakage of gas ,weight sensor provides the level in cylinder , and microcontroller will take the protective and necessary action. All these notable information /status happening has to be conveyed to the user. The simcom300 [6] stores the mobile number of users and distributors. 
It requires only less memory to store and receive the messages.

\subsection{Motor}

The basic principle of DC motor [7] is the creation of rotating magnet inside the mobile part of the motor, rotar. Motor indicates fixed magnet and rotar indicates rotating magnet. The power for the stator electromagnet is supplied by separate DC source. The relative angle between these magnets is maintained near 90 degrees. When gas leak occurs this monitoring system senses the leak by means of sensor and the value is given to the microcontroller.

When gas leak occurs this monitoring system senses the leak by means of sensor and the value is given to the microcontroller.

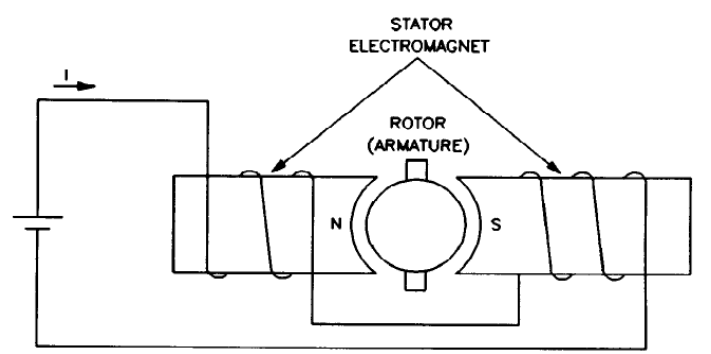

Figure 8: DC motor with electromagnet as stator

The value of lower and higher level of leakage is given in terms of binary format. Then the instruction is given to the motor to close the knob. Then after this controlling measure the leakage message is sent to the user and fire station. At the same time electric current is shutdown by the relay

\section{Operation of Monitoring and Detection System}

\subsection{Detection system:}

In the detection system the MQ6 gas sensor is used which is sensible to LPG, isobutene and propane gases. This sensor sends a signal (digital pulse) to the microcontroller when gas is being leaked. An alert message is sent through the GSM[8][9] to the user and a buzzer alarm is activated in the room. This alarm produces huge sound which drops down the attention of user and neighbors in current leak/fire accidents. These alert messages will be displayed on LCD

Simultaneously, LPG regulator fitted to the cylinder is automatically turned off using a relayed DC motor to avoid more leakage from cylinder.

\subsection{Refilling of cylinder:}

The LPG cylinder refilling unit comprises mainly the weight sensor, which is coupled with to the ATmega328p microcontroller. When the weight of the cylinder reaches the below the predetermined value the GSM modem interfaced to the microcontroller sends booking request to the distributor.

The distributor will verify the validity of customer in the database an accordingly an acknowledgement message is sent through GSM modem to the user automatically.

\section{Experimental Setup}

ATmega328P is the base of the system. The input given to the microchip are the output of gas sensor MQ6 and load cell L6D.The output of the controller are given to the simcom300 and LCD 16*2 display. The Output of gas sensor is given to the INT0 pin of ATmega328p, thus the higher priority is given to the leakage detection. The weight sensor is amplified and digitized by analog to digital converter and is given to the port pins of controller.

The receiver and transmitter pins of GSM are connected to the Tx and Rx pins of ATmega328p respectively. The output is shown on LCD display which is operated in 4-bit mode together enable pins of display are connected to controller. For the protection circuitry exhaust fan is provided with controller. The output from the gas sensor drives this protection circuitry which switch on the exhaust fan when gas leak occurs.

\section{Result}

Monitoring and detection system is proposed and when a small leak occurs, the system sensor detects the leakage (the range is between 400-600 ppm) and sends the alert SMS to the user and activates the alarm and provides the protection circuitry (Exhaust fan).controls the knob of cylinder using relay DC motor. Alternatively 
the system monitors the LPG level of cylinder, automatically books the cylinder when it reaches the lower weight $0.5 \mathrm{~kg}$.

\section{Conclusion}

The system provides control action by closing the regulator knob, after that the system sends a alert message to the user and fire station within short time of leakage. It has more advantageous function than the existing system thus the real-time automatic approach is proposed in case of rebooking of cylinder. This monitoring and detection system is proposed mainly to meet the safety standards and to avoid fire accidents because of leakage.

\section{Future work}

This monitoring system can be further enhanced by using Bluetooth in place of GSM to send the alert messages to user, which supports the another real-time application. For industrial purposes mobile robot can be developed for detecting multiple gas concentrations. Addition to gas sensor temperature sensor can also be used which detects the high pressure gas in cylinder pipe, display the alert SMS when high temperature is reached.

\section{References}

[1] http://edugreen.teri.res.in/explore/n_renew/lpg.htm, http://barabanki.nic.in/bbkgas/aboutlpg.asp.

[2] http://www.pipelineandgasjournal.com/

[3] http://playground.arduino.cc/

[4] V. Ramya and B. Palaniappan, "Embedded system for Hazardous gas detection and Alerting," in Proc. of International Journal of Distribted and parallel system(IJDPS), vol. 3, no. 3, May 2012.

[5] www.indane.co.in, www.hpgas.co.in

[6] H. Huang, H. Bainand S. Zhu, "A Greenhouse Remote Monitoring System Based on GSM," in Proc. of IEEE International Conference on information management, pp. 357-360, 2011.

[7]ftp://ftp.dei.polimi.it/outgoing/Massimo.Ghioni/Power\%20Electronics\%20/Motor\%20control/DC/DC\%20motors\%20and\%20generators. pdf

[8] http://www.engineersgarage.com/contribution/microcontroller-based-lpg-gas-detector-using-gsm-module, S. Rajitha, T. Swapna, "Security alert system using GSM for gas leakage"International Journal of VLSI and Embedded Systems-IJVES

[9] Fraiwan, L.; Lweesy, K.; Bani-Salma, A.Mani, N, "A wireless home safety gas leakage detection system", Proc. of 1st Middle East, Conference on Biomedical Engineering, pp.11-14, 2011.

[10] Sheikh Rafik Manihar, Komal Prasad Dewagan, Jayant Rajpurohit Multiple Gas journal AnalyzerInternational Journal of Modern Engineering Research (IJMER) Vol.2, Issue.4, July-Aug. 2012 pp-2753-2755

[11] Pal-Stefan Murvay, Ioan Silea, "A Survey on gas leak detection and localization techniques," Journal of Loss Prevention in the Process Industries, vol. 25, no. 6, pp. 966-973, Nov. 2012. 